\title{
Single-chain human gonadotropin analogs induce follicle development in sheep
}

\author{
Elyse P Lemke, Betty M Adams, Albina Jablonka-Shariff ${ }^{\mathbf{1}}$, Irving Boime ${ }^{\mathbf{1}}$ and Thomas E Adams \\ Department of Animal Science, University of California, Davis, California 95616, USA \\ ${ }^{1}$ Department of Molecular Biology and Pharmacology, Washington University School of Medicine, St Louis, Missouri 63110, USA \\ (Correspondence should be addressed to T E Adams; Email: teadams@ucdavis.edu)
}

\begin{abstract}
The biopotency of single-chain analogs of human hFSH, human chorionic gonadotropin (hCG), and a dually active gonadotropin construct $(\mathrm{FcCG} \beta \alpha)$ was examined. Sheep (bwt $=61 \cdot 4 \pm 1 \cdot 1 \mathrm{~kg} ; n=6$ ewes $/$ treatment) received a single injection ( $5 \mathrm{IU} / \mathrm{kg}$, i.v.) of the hFSH analog $(\mathrm{Fc} \alpha)$, the hCG analog $(\mathrm{CG} \beta \alpha), \mathrm{FcCG}_{\mathrm{C}} \beta \alpha$, or $\mathrm{F}_{\mathrm{C}} \alpha$ and $\mathrm{CG} \beta \alpha$. Control animals received conditioned media. Ovulation was induced 3 days after analog administration using hCG (1000 IU, i.v.). Basal serum concentrations of estradiol $\left(\mathrm{E}_{2}\right)$ were maintained in control animals. Neither Fc $\alpha$ nor CG $\beta \alpha$ alone induced significant $\mathrm{E}_{2}$ production during the pre-hCG period. Conversely, serum concentrations of $\mathrm{E}_{2}$ were increased $(P<0 \cdot 05) 2$ days after administration of FcCG $\beta \alpha$ or $F_{C} \alpha+$ $\mathrm{CG} \beta \alpha$. Although $\mathrm{P}_{4}$ concentrations were maintained at basal levels in control animals, significant increase was noted in all

other treatment groups during the post-hCG period. Final ovarian weight was significantly increased $(P<0 \cdot 05)$ in animals receiving $\mathrm{Fc}_{\mathrm{C}} \alpha$, Fc $\alpha+\mathrm{CG} \beta \alpha$, or $\mathrm{FcCG} \beta \alpha$, but not $\mathrm{CG} \beta \alpha$ alone. Most of the ovarian enlargement was attributed to the formation of corpora lutea. Collectively, these observations demonstrate that the single-chain analogs of the human gonadotropins are active in sheep. The construct with singular FSH activity supports follicle development but not $E_{2}$ production. Conversely, the construct that incorporates $\beta$-domains from both CG and FSH has dual activity. The long-lived nature of the single-chain constructs suggests that these recombinant gonadotropins may be effective alternatives to pituitary- or placenta-derived gonadotropins in outof-season breeding and/or superovulation protocols.

Journal of Endocrinology (2008) 196, 593-600
\end{abstract}

\section{Introduction}

The pituitary-derived gonadotropic hormones, luteinizing hormone (LH), and follicle-stimulating hormone (FSH), are non-covalently linked heterodimeric proteins composed of a common $\alpha$-subunit and a hormone-specific $\beta$-subunit (Pierce \& Parsons 1981). Both gonadotropins undergo extensive coand post-translational processing, including formation of multiple intrachain disulfide bridges, asparagine $(\mathrm{N})$-linked glycosylation, and assembly of the subunits into the dimeric configuration (Hearn \& Gomme 2000). Human LH shares a high degree of structural similarity with the placenta-derived gonadotropin, human chorionic gonadotropin (hCG). Indeed, the sequence homology of the $\beta$-subunits of hLH and hCG is more than $80 \%$. A distinctive feature of CG $\beta$ is a peptide extension at the carboxy (C) terminus. The C-terminal peptide (CTP) and its associated serine (O)-linked oligosaccharide chains markedly reduce the rate of clearance of hCG and extend its functional life (Matzuk et al. 1990).

The gonadotropic hormones exert a trophic effect on gonadal tissue and maintain the structural and functional integrity of the ovary and testis. In sheep, ovarian weight is dramatically reduced, and follicle maturation and ovulation are blocked after the removal of gonadotropin support by hypothalamo-pituitary disconnection (Hudson et al. 1999), hypophysectomy (Dufour et al. 1979), immunoneutralization of gonadotrophin-releasing hormone (GnRH; Sakurai et al. 1992), or administration of GnRH antagonists (Campbell et al. 1998). These anti-gonadal responses are reversed by administration of supplemental gonadotropic stimuli (Fry et al. 1988, Campbell et al. 1998). The magnitude of the ovarian response increases with progressive increase in the level of exogenous gonadotropin administration and high levels of supplemental FSH induce a superovulatory response (McGowan et al. 1985, Hudson et al. 1999).

The administration of exogenous gonadotropin is commonly used to enhance the fertility of humans and domestic species (Driancourt 2001, Mapletoft et al. 2002, Palagiano et al. 2004). Indeed, supplemental gonadotropins are essential components of multiple ovulation embryo transfer protocols used to enhance the fertility of domestic and exotic animals (Driancourt 2001, Mapletoft et al. 2002). The common hormone preparations (Boland et al. 1991, Lunenfeld 2004) used for this purpose are gonadotropins extracted from the pituitary tissue of sheep or pigs, the plasma or urine of pregnant women (hCG) or mares (equine chorionic 
gonadotropin, eCG), or the urine of post-menopausal women (human menopausal gonadotropin, hMG).

Gonadotropins derived from blood, urine, or pituitary tissue vary in potency, purity, and level of contamination with pathogenic agents or vectors of disease (Murphy et al. 1984, Manning et al. 1987, Phillips et al. 1993, Ludwig et al. 2002). Recombinant gonadotropin preparations circumvent many of these concerns (Daya 2004, Lunenfeld 2004). However, the efficiency of gonadotropin production from cells in culture is often low (Corless et al. 1987). The rate-limiting step in gonadotropin biosynthesis is assembly of the $\alpha$ - and $\beta$-subunits into a functional heterodimer (Garcia-Campayo et al. 1997). Subunit dimerization occurs in the endoplasmic reticulum and even under optimal conditions only about $25 \%$ of the subunits assemble properly (Bedows et al. 1992, Ruddon et al. 1996). The synthesis of single-chain gonadotropins bypasses the dimerization step and, as a consequence, increases the efficiency of in vitro production.

Single-chain analogs of conventional gonadotropins are produced by transfecting Chinese hamster ovary (CHO) cells with a gene construct that links the coding portions of the $\alpha$ - and $\beta$-subunit genes (Garcia-Campayo \& Boime $2001 b$ ). The linker sequence used in the constructs discussed here is the exon encoding the CTP region of CG $\beta$. The CTP segment and the associated $O$-linked oligosaccharide chains markedly increase the in vivo activity of the gonadotropins by reducing the rate of clearance (LaPolt et al. 1992, Joshi et al. 1995). The single-chain technology has been extended to include the union of genes encoding two or more types of $\beta$-subunits. For example, a construct containing genes encoding the $\alpha, \mathrm{CG} \beta$, and FSH $\beta$ subunits produces a protein that interacts with both $\mathrm{LH}$ and $\mathrm{FSH}$ receptors. Thus, this novel chimeric gonadotropin has both $\mathrm{LH}$ and FSH activities in vitro (Kanda et al. 1999, Garcia-Campayo \& Boime 2001a).

In the study described here, we examined the in vivo activity of the single-chain human gonadotropins with LH or FSH activity. In addition, we examined follicle development and ovulation in sheep receiving a unique chimeric gonadotropin with both $\mathrm{LH}$ and FSH activities. The results of these studies demonstrate that the single-chain analog with dual activity induces profound follicle development in sheep. The efficient and consistent production of this chimeric protein in a pure and pathogen-free form, along with its inherent dual activity and long functional life, may make this unique chimeric gonadotropin an effective alternative to tissue-derived gonadotropins in out-of-season breeding and superovulation protocols.

\section{Materials and Methods}

\section{Animals}

The biological activity of recombinant single-chain gonadotropins was evaluated using 30 yearling ewes (mean weight $=$ $61 \cdot 4 \pm 1 \cdot 1 \mathrm{~kg})$. Animals were maintained under natural lighting in open-sided pens and afforded free access to water and alfalfa pellets supplemented with cereal grains and vitamin and mineral premix. The study was conducted in late fall and early winter, a period when reproductive function is at its height in sheep at this latitude $\left(38^{\circ} \mathrm{N}\right)$. All experimental procedures involving the use of animals were conducted in accordance with NIH Guidelines and were reviewed and approved by the Animal Use and Care Committee for the University of California, Davis.

\section{Cannulation}

Polyethylene cannulae (Intramedic PE 190, Clay Adams, Parsippany, NJ, USA) were inserted into the external jugular vein, 2 days before gonadotropin administration. The cannulae were used for blood collection and administration of anti-GnRH and recombinant gonadotropin. The cannulae were protected by a sheath of plastic tubing that extended to the exterior of the animal holding area. Animals were freely mobile at the end of the $1 \mathrm{~m}$ lead.

\section{Estrous synchronization}

Ovarian status and estrous activity of ewes were synchronized using Lutalyse (PGF2 $\alpha$; Upjohn, Kalamazoo, MI, USA) and progesterone-containing intravaginal implants (Eazi-Breed CIDR (Type G), InterAg, Hamilton, NZ, USA) according to the treatment paradigm described by Van Cleeff et al. (1998).

\section{Construction of single-chain gonadotropins}

The single-chain analogs of human FSH (hFSH $\beta-\mathrm{CTP}-\alpha$; $\left.F_{c} \alpha\right)$, hCG (hCG $\left.\beta-\alpha ; C G \beta \alpha\right)$, and a chimeric gonadotropin incorporating the $\beta$-subunits of both $\mathrm{CG}$ and $\mathrm{FSH}$ (hFSH $\beta$ $\mathrm{CTP}-\mathrm{hCG} \beta-\alpha$; FcCG $\beta \alpha$ ) were generated as described by Boime et al. (Sugahara et al. 1995, 1996, Kanda et al. 1999). Briefly, these chimeric proteins were produced from gene constructs generated by joining cDNA encoding the $\beta$ - and $\alpha$-subunits through a linker sequence that encodes the carboxy-terminal portion of hCG. CHO cells transfected with constructs encoding $\mathrm{Fc}_{\mathrm{c}} \alpha, \mathrm{CG} \beta \alpha$, or FcCG $\beta \alpha$ were grown to confluency and the proteins in the conditioned media concentrated by centrifugation (Centricon Plus-70, Millipore Corp., Billerica, MA, USA).

\section{Immunization against $\mathrm{GnRH}$}

Antibodies directed against GnRH were generated in castrated male sheep actively immunized against a $\mathrm{GnRH}$ carrier protein conjugate using the procedure described previously (Adams \& Adams 1986). The antisera were collected and processed for passive immunization as described by Sakurai et al. (1992). The pool of anti-GnRH sera used in these studies had high antibody titer $(0.1 \mathrm{ml}$ serum diluted 1:60 000 bound $44 \cdot 8 \%$ of ${ }^{125} \mathrm{I}-\mathrm{GnRH}$ added in a final volume of $0.2 \mathrm{ml}$ ). Previous studies have demonstrated that 
administration of $\mathrm{GnRH}$ antisera in amounts comparable with the levels used in this study results in a block to follicle development and ovulation (Sakurai et al. 1992).

\section{Experimental design}

We hypothesized that the single-chain chimeric gonadotropin containing components of both hCG and hFSH would express dual activity and induce follicle development in sheep. The experimental protocol is presented schematically in Fig. 1. Briefly, yearling ewes were assigned at random to one of five treatment groups ( $n=6$ ewes/group). Ovarian status and estrous activity of ewes were synchronized as described above. To negate the confounding effect of endogenous gonadotropins, animals were passively immunized against $\mathrm{GnRH}$ (150 ml/sheep, i.v.) 1 day before CIDR removal. The antiGnRH serum was obtained from castrated male sheep actively immunized against $\mathrm{GnRH}$ as described above. Animals received $\mathrm{CG} \beta \alpha, \mathrm{Fc} \alpha$, FcCG $\beta \alpha$, or $\mathrm{CG} \beta \alpha$ and $\mathrm{Fc}_{\mathrm{C}} \alpha$ in combination at CIDR removal. Chimeric gonadotropins were administered at a dose of $5 \mathrm{IU} / \mathrm{kg}$ (i.v). The activity of the single-chain proteins was assessed using the immunoassay procedures discussed below. Control animals (Group 1) received an equivalent concentration of protein isolated from the conditioned media of non-transfected $\mathrm{CHO}$ cells. Previous studies have demonstrated that the endogenous surge of LH is not evident in sheep passively immunized against GnRH (Sakurai et al. 1992). Therefore, a bolus of hCG (1000 IU, i.v.) was administered 3 days after CIDR removal to

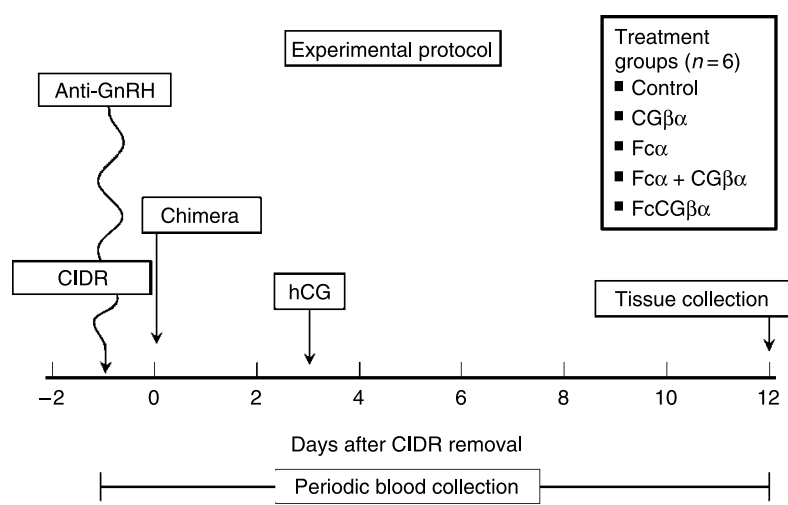

Figure 1 The estrous activity of 30 yearling ewes was synchronized using PGF $2 \alpha$ and progesterone-containing vaginal inserts (CIDRs). Secretion of endogenous gonadotropins was suppressed by passive immunization with antisera directed against GnRH (anti-GnRH) 1 day prior to CIDR removal. Animals ( $n=6$ ewes/group) received recombinant gonadotropin (CG $\beta \alpha, F_{C} \alpha, F_{C C G} \beta \alpha$, or $C G \beta \alpha+F_{C} \alpha$ in combination) at CIDR removal. Chimeric gonadotropins were administered at a dose of $5 \mathrm{lU} / \mathrm{kg}$ (i.v.). Control animals received an equivalent concentration of protein isolated from the conditioned media of non-transfected $\mathrm{CHO}$ cells. Human chorionic gonadotropin (hCG, $1000 \mathrm{IU}$, i.v.) was administered 3 days after chimera administration to simulate the preovulatory surge of $\mathrm{LH}$. Blood samples were collected at 6 -h interval for 6 days after CIDR removal and daily thereafter. Ovarian tissue was collected 11 days after administration of the chimeric gonadotropins. simulate the preovulatory surge of LH. This LH-like stimulus induces ovulation in sheep deficient in endogenous gonadotropins and receiving exogenous FSH or eCG to promote follicle development (Fry et al. 1988, Picton et al. 1990). Blood samples were collected before, and at 6-h interval for 6 days after, chimera administration. Daily blood samples were collected for an additional 5-day period. Blood was allowed to clot at $4{ }^{\circ} \mathrm{C}$, and serum was isolated by centrifugation. Serum samples were rapidly frozen and stored at $-20^{\circ} \mathrm{C}$ for later analysis. Animals were stunned by means of electrical shock, killed by exsanguination, and ovaries were collected 11 days after administration of the chimeric gonadotropins.

\section{Hormone analysis}

Serum concentrations of $\mathrm{P}_{4}$ and estradiol $\left(\mathrm{E}_{2}\right)$ were determined using previously validated RIAs (Adams et al. 1988, Sakurai et al. 1992). The LH and FSH activities in the single-chain analogs of the human gonadotropins were determined using dimer-specific RIAs for human LH and FSH (Diagnostic Products Corp., Los Angeles, CA, USA).

\section{Statistical analysis}

The mixed procedure in SAS was used to perform all statistical analyses. Analysis of $\mathrm{E}_{2}$ and $\mathrm{P}_{4}$ was performed using a repeated measures analysis including the fixed effects of time, treatment, and their interaction and the random effect of animal nested within the treatment $X$ time. Differences between treatments within a time period were determined by a Bonferroni adjustment of the probability of difference calculated by the pdiff option of SAS. The analyses of area under the $E_{2}$ peak, duration of elevated $E_{2}$, and all ovarian measurements employed one-way ANOVA models with treatment as the sole fixed effect. Significant differences between treatments were determined by $t$-test with the pdiff option and Tukey's adjustment.

\section{Results}

\section{Passive immunization against $\mathrm{G} n \mathrm{RH}$}

An important aspect of our animal model involved the use of anti-GnRH sera to minimize secretion of endogenous gonadotropins. The anti-GnRH titer at chimera administration was $41 \cdot 0 \pm 6 \%$ (percentage of ${ }^{125} \mathrm{I}-\mathrm{GnRH}$ bound by a 1:1000 dilution of serum). Antibody titer decreased gradually during the experimental period and at tissue collection (12 days after passive immunization), the anti-GnRH titer was $21 \cdot 9 \pm 0 \cdot 4 \%$. The maximal titer and the rate of reduction over time did not differ $(P>0 \cdot 05)$ among treatment groups.

The effectiveness of the anti-GnRH treatment is indicated by the lack of ovarian response to CIDR removal noted in control animals receiving gonadotropin-free conditioned media. Indeed, serum concentrations of $E_{2}$ in control animals 
were maintained at basal levels throughout the study period (Figs 2 and 3). Similarly, neither follicle development beyond the $3 \mathrm{~mm}$ stage nor corpora lutea were noted in ovarian tissue of control animals collected 11 days after CIDR removal. Serum concentrations of $\mathrm{P}_{4}$ were also maintained at basal levels throughout the study period in control animals (Fig. 4). Collectively, these observations indicate that the increased secretion of LH and FSH that normally accompanies CIDR removal is blocked by passive immunization.

\section{Single-chain gonadotropin-induced $E_{2}$ response}

The effect of the single-chain human gonadotropin homologs on ovarian steroidogenesis during the 3-day period after chimera administration is illustrated in Fig. 2. As noted above, $\mathrm{E}_{2}$ secretion was maintained at pre-treatment levels in control animals receiving gonadotropin-free conditioned media. Basal concentrations of $\mathrm{E}_{2}$ were also evident in animals receiving the single-chain analogs of $\mathrm{hFSH}(\mathrm{Fc} \alpha)$ or hCG $(C G \beta \alpha)$. Conversely, serum concentrations of $E_{2}$ increased markedly within $48 \mathrm{~h}$ of chimera administration in animals receiving $F_{c} \alpha$ and $C G \beta \alpha$ concurrently. A similar steroidogenic response was noted in sheep treated with the analog that incorporates the $\beta$-subunits of both hCG and hFSH $\left(\mathrm{F}_{\mathrm{C}} \mathrm{CG} \beta \alpha\right)$ into a dually active single-chain gonadotropin.

Previous studies have demonstrated that the ovulatory surge of LH is blocked in sheep passively immunized against GnRH (Sakurai et al. 1992). As a consequence, we administered supplemental hCG (1000 IU, i.v.) 3 days after chimera administration to simulate the LH surge and induce ovulation of follicles that developed during the period after CIDR removal. The initial phase of $\mathrm{E}_{2}$ production was abruptly terminated by hCG administration in animals receiving either

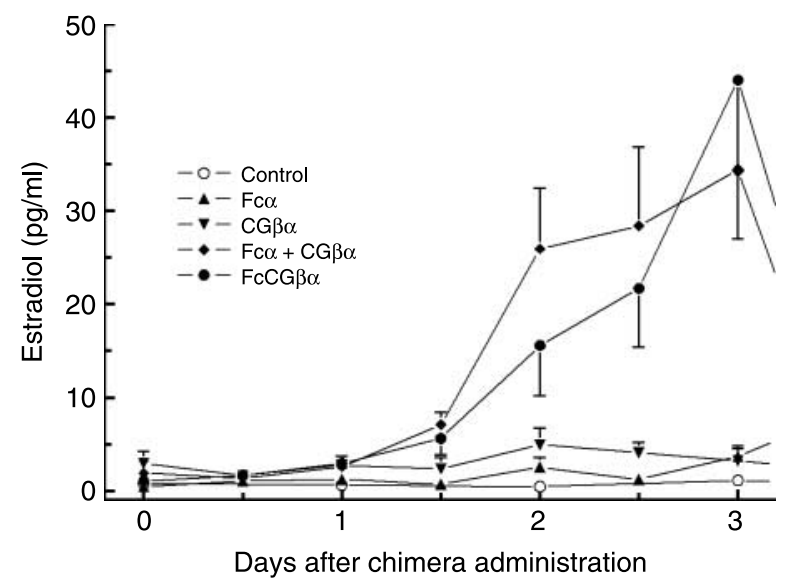

Figure 2 Serum concentration of estradiol during the preovulatory period in yearling ewes receiving recombinant single-chain human gonadotropins $(5 \mathrm{IU} / \mathrm{kg}$, i.v.) at CIDR removal (day 0). Animals $(n=6$ ewes/treatment) received either CG $\beta \alpha(\boldsymbol{\nabla}), \operatorname{Fc} \alpha(\boldsymbol{\Delta})$, FcCG $\beta \alpha$ $(\boldsymbol{)})$, or $\mathrm{CG} \beta \alpha+\mathrm{F}_{\mathrm{c} \alpha}$ in combination $(\bullet)$. Control animals $(\mathrm{O})$ received an equivalent concentration of protein isolated from the conditioned media of non-transfected $\mathrm{CHO}$ cells.

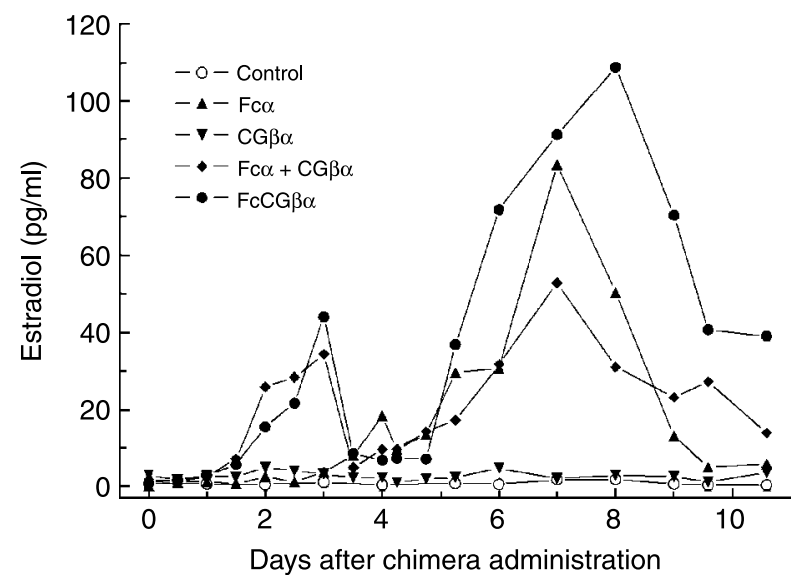

Figure 3 Serum concentration of estradiol during the full study period in yearling ewes receiving recombinant single-chain human gonadotropins (5 IU $/ \mathrm{kg}$, i.v.) at CIDR removal (day 0). Animals $\left(n=6\right.$ ewes/treatment) received either CG $\beta \alpha(\boldsymbol{\nabla}), F_{C} \alpha(\boldsymbol{\Delta}), F_{C C G} \beta \alpha$ $(\bullet)$, or CG $\beta \alpha+F_{C} \alpha$ in combination $(\bullet)$. Control animals $(O)$ received an equivalent concentration of protein isolated from the conditioned media of non-transfected $\mathrm{CHO}$ cells. The preovulatory surge of LH was simulated by administration of hCG (1000 IU, i.v.) 3 days after chimera administration.

the dually active chimera or a combination of the singly active analogs (Fig. 3). The nadir in $\mathrm{E}_{2}$ concentration was noted 12-24 h after hCG administration. A prolonged secondary phase of $\mathrm{E}_{2}$ production was noted in animals treated with $F_{C C G} \beta \alpha$ or the $F_{c} \alpha+C G \beta \alpha$ combination. Although a posthCG increase in $\mathrm{E}_{2}$ production was not evident in control animals or animals receiving CG $\beta \alpha$ alone, serum concentrations of $\mathrm{E}_{2}$ were significantly increased in the post-hCG period in animals receiving only $\mathrm{F}_{\mathrm{c} \alpha} \boldsymbol{\alpha}$ at chimera administration.

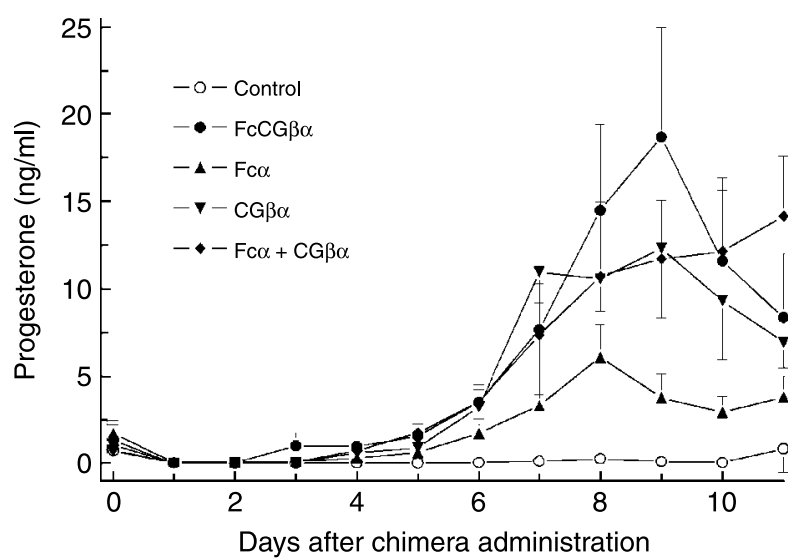

Figure 4 Serum concentration of progesterone in yearling ewes receiving recombinant single-chain human gonadotropins $(5 \mathrm{IU} / \mathrm{kg}$, i.v.) at CIDR removal (day 0). Animals ( $n=6$ ewes/treatment) received either $\mathrm{CG}_{\beta} \alpha(\boldsymbol{\nabla}), \mathrm{F}_{\mathrm{C}} \boldsymbol{\alpha}(\boldsymbol{\Delta})$, $\mathrm{FCCG}_{\mathrm{CC}} \beta \alpha(\boldsymbol{\bullet})$, or $\mathrm{CG} \beta \alpha+\mathrm{F}_{\mathrm{C}} \alpha$ in combination $(\bullet)$. Control animals $(\mathrm{O})$ received an equivalent concentration of protein isolated from the conditioned media of non-transfected $\mathrm{CHO}$ cells. The preovulatory surge of $\mathrm{LH}$ was simulated by administration of hCG (1000 IU, i.v.) 3 days after chimera administration. 
Although serum concentrations of $\mathrm{P}_{4}$ were maintained at basal levels throughout the study period in control animals receiving gonadotropin-free conditioned media, $\mathrm{P}_{4}$ concentrations during the post-hCG period were significantly increased in all other treatment groups. This suggests that the simulated ovulatory surge did induce ovulation and subsequent development of corpora lutea.

\section{Single-chain gonadotropins - trophic ovarian response}

The steroidogenic response noted above provides one measure of the biological activity of the chimeric gonadotropins. The gonadotropins also exert a trophic effect on gonadal tissue that is manifest grossly as change in ovarian weight. To assess the trophic response induced by the single-chain gonadotropin analogs, we collected ovarian tissue 11 days after chimera administration. As noted in Fig. 5, total ovarian weight in animals receiving the single-chain chimera with $\mathrm{LH}$ activity $(\mathrm{CG} \beta \alpha)$ did not differ from the ovarian weight in control animals. However, final ovarian weight was markedly increased in all the animals receiving supplemental FSH support. Indeed, final ovarian weight in groups receiving $\mathrm{Fc}_{\mathrm{c}} \alpha$ alone, or in combination with CG $\beta \alpha(\mathrm{Fc} \alpha+\mathrm{CG} \beta \alpha)$, did not differ from the final ovarian weight in animals receiving the dually active $(\mathrm{FcCG} \beta \alpha)$ chimera. Moreover, final ovarian weight in the latter three groups was eight- to tenfold greater than the ovarian weight noted in control animals. The marked increase in ovarian mass noted in animals receiving supplemental FSH (Fc $\alpha, F_{C} \alpha+C G \beta \alpha$, and $\left.F_{c C G} \beta \alpha\right)$ can be attributed, in large part, to the large number of corpora lutea

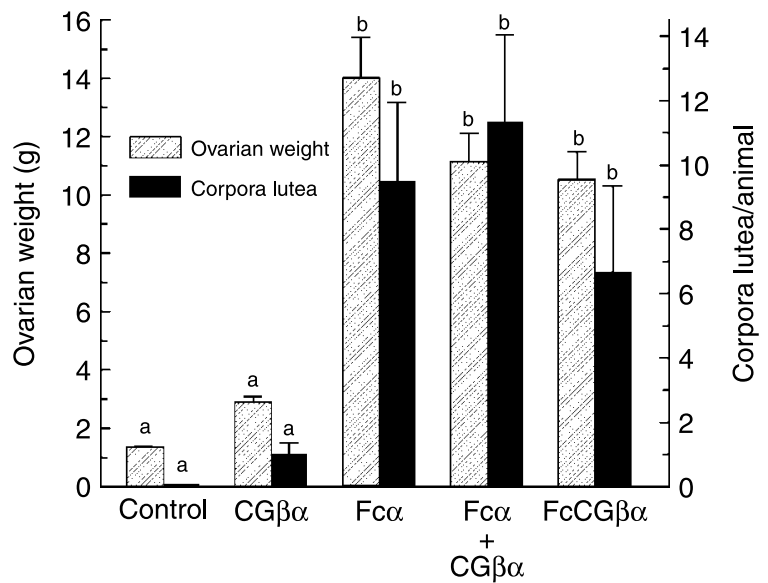

Figure 5 Final ovarian weight and number of corpora lutea noted at slaughter in yearling ewes receiving recombinant single-chain human gonadotropins ( $5 \mathrm{IU} / \mathrm{kg}$, i.v.) at CIDR removal (day 0$)$. Animals ( $n=6$ ewes/treatment) received either CG $\beta \alpha$, FC $\alpha$, FCCG $\beta \alpha$, or CG $\beta \alpha+F_{C} \alpha$ in combination at CIDR removal. Control animals received an equivalent concentration of protein isolated from the conditioned media of non-transfected $\mathrm{CHO}$ cells. The preovulatory surge of $\mathrm{LH}$ was simulated by administration of hCG (1000 IU, i.v.) 3 days after CIDR removal and ovarian tissue was collected 8 days thereafter. The superscripts $a$ and $b$ denote significant difference at $P<0.05$ level. evident in the tissue (Fig. 5). Although corpora lutea were not evident on the ovarian tissue of control animals, they were noted in all other groups. The most profound increase was noted in the groups receiving supplemental FSH support (Fc $\alpha$, $\mathrm{F}_{\mathrm{C}} \alpha+\mathrm{CG} \beta \alpha$, and $\left.\mathrm{FcCG}_{\mathrm{C}} \beta \alpha\right)$ during the period preceding hCG administration. Interestingly, numerous large follicles were also evident on the surface of the ovaries collected from FSH-treated animals ( $F_{C} \alpha, F_{C} \alpha+C G \beta \alpha$, and $\left.F_{C} C G \beta \alpha\right)$. This persistent follicle development also contributed to the enhanced ovarian weight noted in these treatment groups.

\section{Discussion}

The results of this study clearly demonstrate that the singlechain analogs of the human gonadotropins have potent bioactivity in sheep. The analogs with singular LH or FSH activity act in concert to promote $\mathrm{E}_{2}$ production. Interestingly, the chimeric protein incorporating both FSH $\beta$ and CG $\beta$ has dual activity in the ovine model and induces profound follicle development and $\mathrm{E}_{2}$ synthesis. Collectively, these observations indicate that the recombinant single-chain gonadotropin analogs may be useful alternatives to tissuederived gonadotropins in treatment regimens designed to improve the reproductive efficiency of domestic species.

Estrogen production is an effective measure of the potency of the single-chain chimeric gonadotropins. As in other species (Richards 1980), $E_{2}$ synthesis in sheep requires input from both the thecal and granulosa cells (Baird 1977, 1983, England et al. 1981). The essential role of the gonadotropins in ovarian function is illustrated by the arrest of follicle development and $\mathrm{E}_{2}$ synthesis in mature ewes made deficient in the gonadotropins by hypophysectomy (Draincourt et al. 1987), hypothalamopituitary disconnection (Hudson et al. 1999), immunoneutralization of endogenous GnRH (McNeilly et al. 1986), or administration of long-lived GnRH agonists (McNeilly \& Fraser 1987) or antagonists (Campbell et al. 1998). Moreover, follicle development and $\mathrm{E}_{2}$ synthesis are reinstated in gonadotropin-deficient sheep by administration of LH and FSH (Campbell et al. 1998). Conversely, follicle development, but not $\mathrm{E}_{2}$ synthesis, is noted in gonadotropin-deficient ewes receiving supplemental FSH alone. These observations indicate that follicle development is supported by FSH, but $\mathrm{E}_{2}$ synthesis requires both gonadotropins acting in synergy.

The synergism between $\mathrm{LH}$ and $\mathrm{FSH}$ that drives $\mathrm{E}_{2}$ production is illustrated by the results noted in the study presented here. Neutralization of endogenous GnRH by passive immunization arrested follicle development at the 2-3 mm stage and blocked $E_{2}$ production. Single-chain chimeras having $\mathrm{CG}$ or FSH activity were not effective in inducing appreciable $\mathrm{E}_{2}$ production during the 3-day period following administration of chimeric gonadotropin. However, concurrent treatment with both recombinant gonadotropins resulted in a marked increase in $\mathrm{E}_{2}$ secretion. Similarly, the single-chain chimera with dual activity also induced a significant increase in $\mathrm{E}_{2}$ synthesis. Collectively, 
these data demonstrate that the single-chain analogs of human $\mathrm{CG}$ and FSH are biologically active in sheep. In addition, the single-chain chimera that contains components of $\mathrm{CG}$ and $\mathrm{FSH}$ expresses bifunctional activity in vivo.

Although the single-chain analog of FSH does not induce $\mathrm{E}_{2}$ production in the absence of $\mathrm{LH}$, follicle development is less dependent on concurrent stimulation by FSH and LH. Indeed, ovarian weight, follicular activity, and number of corpora lutea did not differ between animals receiving $F_{c} \alpha$ alone and those receiving either the dually active chimera or the $\mathrm{Fc}_{\mathrm{c}} \alpha+\mathrm{CG} \beta \alpha$ combination. These observations are consistent with previous reports noting significant FSH-induced follicle development without coincident estrogen production in LH-deficient sheep (Picton et al. 1990, Campbell et al. 1998), cattle (Hampton et al. 2004), and primates (Karnitis et al. 1994, Zelinski-Wooten et al. 1995).

A striking feature noted in animals receiving the Fc $\alpha+$ $\mathrm{CG} \beta \alpha$ combination was a biphasic pattern of $\mathrm{E}_{2}$ production. A similar pattern was also noted in animals receiving the chimeric protein with dual activity. The two phases of $E_{2}$ production in these animals was punctuated by hCG-induced ovulation. The magnitude of the second phase of estrogen production was five to ten times higher than level of estrogen production common during the normal follicular phase of the ovine estrous cycle. A post-hCG surge of $\mathrm{E}_{2}$ was also noted in animals receiving the single-chain analog of FSH. This seems likely to reflect that synergy between the LH activity of the hCG administered on day 3 and the FSH activity that is intrinsic to the chimera. The secondary surge of $\mathrm{E}_{2}$ is likely not due to hCG alone since no such surge was noted in animals receiving conditioned media at CIDR removal.

The biphasic pattern of $\mathrm{E}_{2}$ production is likely reflective of the maturation and hCG-induced rupture of one cohort of antral follicles and the subsequent maturation of a second cohort. A similar biphasic pattern of follicle development and $\mathrm{E}_{2}$ secretion has been noted in heifers treated with another long-lived gonadotropin, eCG (Echternkamp 1978, Saumande 1980, Kaneko et al. 1992).

The magnitude and extended duration of the estrogenic response is likely a consequence of the long-lived nature of both hCG and the single-chain gonadotropins. Although hCG shares many features in common with $\mathrm{LH}$, the unique peptide extension at the carboxy terminus of the $\beta$-subunit markedly increases the half-life of hCG (Yen et al. 1968). Since Fc $\alpha$ and CG $\beta \alpha$ each have a single CTP cassette and FcCG $\beta \alpha$ has two CTP units, the half-life of the single-chain gonadotropin analogs is likely to be increased. Certainly, the dramatic post-hCG surge of $\mathrm{E}_{2}$ production and the persistent follicular activity evident at slaughter are consistent with the long-lived nature of the chimeras. Moreover, preliminary observations in sheep suggest that the half-lives of $F c \alpha$ and FcCG $\beta \alpha$ are about tenfold greater than that of pituitaryderived ovine FSH (Rodriquez \& Adams unpublished).

The long-lived nature of the recombinant proteins is due, at least in part, to the O-linked oligosaccharide chains that are added to the CTP segment during post-translational processing. Indeed, the half-lives of both FSH (LaPolt et al. 1992) and TSH (Joshi et al. 1995, Grossmann et al. 1997) are dramatically extended by addition of the CTP segment to the $\beta$-subunit. In addition, the oligosaccharide chains of recombinant proteins expressed in $\mathrm{CHO}$ cells contain terminal sialic acid residues (Smith et al. 1990). Conversely, the glycoproteins produced by the ovine pituitary typically contain sulfated termini (Green \& Baenziger 1988). The sialylated termini characteristic of recombinant proteins further reduce the rate of clearance by reducing the rate of hepatic extraction (Baenziger et al. 1992, Thotakura \& Blithe 1995).

The dramatic follicular response induced by a single injection of the chimeric protein also reflects the long-lived nature of the single-chain gonadotropin analogs in sheep. Induction of comparable follicular development using pituitary-derived FSH generally requires repetitive or continuous administration (Campbell et al. 1998, D'Alessandro et al. 2001, 2005). Repetitive administration of $\mathrm{hMG}$ is also required to induce a superovulatory response in sheep, suggesting that the urinary forms of human $\mathrm{LH}$ and FSH that comprise hMG have a relatively short half-life in sheep. Indeed, the rate of clearance of human LH in sheep is rapid (de Kretser et al. 1973). Interestingly, the clearance of human LH in sheep is markedly reduced after nephrectomy, suggesting that renal filtration plays an important role in the clearance of pituitary-derived gonadotropins. Although the half-life of human FSH in sheep has not been determined, the rate of clearance of human FSH in cattle is rapid (Lauria et al. 1982). Collectively, these data indicate that pituitary-derived human gonadotropins, like their ovine counterparts, are quickly cleared from the circulation, while single-chain gonadotropin analogs containing one or more CTP cassettes have a much longer half-life. In practical terms, this means that a single injection of the chimera is sufficient to induce a superovulatory response. This represents a significant advantage over the current superovulation protocols that require repetitive administration of ovine, porcine, or human gonadotropins at 12-h interval for 3 days.

Taken together, the observations presented here demonstrate that the single-chain homologs of LH and FSH have activity in sheep. Although neither analog alone increases estrogenic activity, together the two chimeric gonadotropins induce marked and persistent estrogen production. Similarly, follicle development and $\mathrm{E}_{2}$ synthesis are dramatically increased in sheep receiving the chimeric gonadotropin with dual activity. These data indicate that recombinant single-chain gonadotropins with singular or dual activity may be effective alternatives to pituitary or placental gonadotropins in managed breeding and/or superovulation induction protocols.

\section{Acknowledgements}

We are grateful for the skilled technical and clinical assistance of Seth Wegner, Ben Renquist, Carla Rodriquez, and Dana Van Liew. This project was supported by National Research 
Initiative Competitive Grant 5-35203-16274 from the USDA Cooperative State Research, Education, and Extension Service Animal Reproduction Program, and the California Agricultural Experiment Station. The authors declare that there is no conflict of interest that would prejudice the impartiality of this scientific work.

\section{References}

Adams TE \& Adams BM 1986 Gonadotrope function in ovariectomized ewes actively immunized against gonadotropin-releasing hormone $(\mathrm{GnRH})$. Biology of Reproduction 35 360-367.

Adams TE, Quirke JF, Hanrahan JP, Adams BM \& Watson JG 1988 Gonadotrophin secretion during the periovulatory period in Galway and Finnish Landrace ewes and Finnish Landrace ewes selected for high ovulation rate. Journal of Reproduction and Fertility 83 575-584.

Baenziger JU, Kumar S, Brodbeck RM, Smith PL \& Beranek MC 1992 Circulatory half-life but not interaction with the lutropin/chorionic gonadotropin receptor is modulated by sulfation of bovine lutropin oligosaccharides. PNAS 89 334-338.

Baird DT 1977 Evidence in vivo for the two-cell hypothesis of oestrogen synthesis by the sheep Graafian follicle. Journal of Reproduction and Fertility $\mathbf{5 0}$ 183-185.

Baird DT 1983 Factors regulating the growth of the preovulatory follicle in the sheep and human. Journal of Reproduction and Fertility 69 343-352.

Bedows E, Huth JR \& Ruddon RW 1992 Kinetics of folding and assembly of the human chorionic gonadotropin beta subunit in transfected Chinese hamster ovary cells. Journal of Biological Chemistry 267 8880-8886.

Boland MP, Goulding D \& Roche JF 1991 Alternative gonadotrophins for superovulation of cattle. Theriogenology 35 5-17.

Campbell BK, Dobson H \& Scaramuzzi RJ 1998 Ovarian function in ewes made hypogonadal with GnRH antagonist and stimulated with FSH in the presence or absence of low amplitude LH pulses. Journal of Endocrinology 156 213-222.

Van CleeffJ, Karsch FJ \& Padmanabhan V 1998 Characterization of endocrine events during the periestrous period in sheep after estrous synchronization with controlled internal drug release (CIDR) device. Domestic Animal Endocrinology 15 23-34.

Corless CL, Matzuk MM, Ramabhadran TV, Krichevsky A \& Boime I 1987 Gonadotropin beta subunits determine the rate of assembly and the oligosaccharide processing of hormone dimer in transfected cells. Journal of Cell Biology 104 1173-1181.

D’Alessandro AG, Martemucci G, Colonna MA, Borghese A, Terzano MG \& Bellitti A 2001 Superovulation in ewes by a single injection of $\mathrm{pFSH}$ dissolved in polyvinylpyrrolidone (PVP): effects of PVP molecular weight, concentration and schedule of treatment. Animal Reproduction Science $\mathbf{6 5}$ 255-264.

D'Alessandro AG, Martemucci G \& Taibi L 2005 How the FSH/LH ratio and dose numbers in the p-FSH administration treatment regimen, and insemination schedule affect superovulatory response in ewes. Theriogenology 63 1764-1774.

Daya S 2004 Follicle-stimulating hormone in clinical practice: an update. Treatments in Endocrinology 3 161-171.

Draincourt MA, Fry RC, Clarke IJ \& Cahill LP 1987 Follicular growth and regression during the 8 days after hypophysectomy in sheep. Journal of Reproduction and Fertility 79 635-641.

Driancourt MA 2001 Regulation of ovarian follicular dynamics in farm animals. Implications for manipulation of reproduction. Theriogenology $\mathbf{5 5}$ 1211-1239.

Dufour J, Cahill LP \& Mauleon P 1979 Short- and long-term effects of hypophysectomy and unilateral ovariectomy on ovarian follicular populations in sheep. Journal of Reproduction and Fertility 57 301-309.

Echternkamp SE 1978 Stimulation of estrogen and luteinizing hormone secretion in postpartum beef cows. Journal of Animal Science 47 521-531.
England BG, Webb R \& Dahmer MK 1981 Follicular steroidogenesis and gonadotropin binding to ovine follicles during the estrous cycle. Endocrinology 109 881-887.

Fry RC, Clarke IJ, Cummins JT, Bindon BM, Piper LR \& Cahill LP 1988 Induction of ovulation in chronically hypophysectomized Booroola ewes. Journal of Reproduction and Fertility 82 711-715.

Garcia-Campayo V \& Boime I 2001a Independent activities of FSH and LH structurally confined in a single polypeptide: selective modification of the relative potencies of the hormones. Endocrinology 142 5203-5211.

Garcia-Campayo V \& Boime I $2001 b$ Novel recombinant gonadotropins. Trends in Endocrinology and Metabolism 12 72-77.

Garcia-Campayo V, Sato A, Hirsch B, Sugahara T, Muyan M, Hsueh AJ \& Boime I 1997 Design of stable biologically active recombinant lutropin analogs. Nature Biotechnology 15 663-667.

Green ED \& Baenziger JU 1988 Asparagine-linked oligosaccharides on lutropin, follitropin, and thyrotropin. II. Distributions of sulfated and sialylated oligosaccharides on bovine, ovine, and human pituitary glycoprotein hormones. Journal of Biological Chemistry 263 36-44.

Grossmann M, Wong R, Szkudlinski MW \& Weintraub BD 1997 Human thyroid-stimulating hormone (hTSH) subunit gene fusion produces hTSH with increased stability and serum half-life and compensates for mutagenesis-induced defects in subunit association. Journal of Biological Chemistry 272 21312-21316.

Hampton JH, Bader JF, Lamberson WR, Smith MF, Youngquist RS \& Garverick HA 2004 Gonadotropin requirements for dominant follicle selection in GnRH agonist-treated cows. Reproduction 127 695-703.

Hearn MT \& Gomme PT 2000 Molecular architecture and biorecognition processes of the cystine knot protein superfamily. Part I. The glycoprotein hormones. Journal of Molecular Recognition 13 223-278.

Hudson NL, O'Connell AR, Shaw L, Clarke IJ \& McNatty KP 1999 Effect of exogenous FSH on ovulation rate in homozygous carriers or noncarriers of the Booroola FecB gene after hypothalamic-pituitary disconnection or after treatment with a GnRH agonist. Domestic Animal Endocrinology 16 69-80.

Joshi L, Murata Y, Wondisford FE, Szkudlinski MW, Desai R \& Weintraub BD 1995 Recombinant thyrotropin containing a beta-subunit chimera with the human chorionic gonadotropin-beta carboxy-terminus is biologically active, with a prolonged plasma half-life: role of carbohydrate in bioactivity and metabolic clearance. Endocrinology 136 3839-3848.

Kanda M, Jablonka-Shariff A, Sato A, Pixley MR, Bos E, Hiro'oka T, Ben-Menahem D \& Boime I 1999 Genetic fusion of an alpha-subunit gene to the follicle-stimulating hormone and chorionic gonadotropin-beta subunit genes: production of a bifunctional protein. Molecular Endocrinology 13 1873-1881.

Kaneko H, Watanabe G, Taya K \& Sasamoto S 1992 Changes in peripheral levels of bioactive and immunoreactive inhibin, estradiol-17 beta, progesterone, luteinizing hormone, and follicle-stimulating hormone associated with follicular development in cows induced to superovulate with equine chorionic gonadotropin. Biology of Reproduction 47 76-82.

Karnitis VJ, Townson DH, Friedman CI \& Danforth DR 1994 Recombinant human follicle-stimulating hormone stimulates multiple follicular growth, but minimal estrogen production in gonadotropin-releasing hormone antagonist-treated monkeys: examining the role of luteinizing hormone in follicular development and steroidogenesis. Journal of Clinical Endocrinology and Metabolism 79 91-97.

de Kretser DM, Atkins RC \& Paulsen CA 1973 Role of the kidney in the metabolism of luteinizing hormone. Journal of Endocrinology 58 425-434.

LaPolt PS, Nishimori K, Fares FA, Perlas E, Boime I \& Hsueh AJ 1992 Enhanced stimulation of follicle maturation and ovulatory potential by long acting follicle-stimulating hormone agonists with extended carboxylterminal peptides. Endocrinology 131 2514-2520.

Lauria A, Genazzani AR, Oliva O, Inaudi P, Cremonesi F, Monittola C \& Aureli G 1982 Clinical and endocrinological investigations on superovulation induced in heifers by human menopausal gonadotrophin. Journal of Reproduction and Fertility 66 219-225.

Ludwig M, Felberbaum RE, Diedrich K \& Lunenfeld B 2002 Ovarian stimulation: from basic science to clinical application. Reproductive Biomedicine Online 5 (Suppl 1) 73-86. 
Lunenfeld B 2004 Historical perspectives in gonadotrophin therapy. Human Reproduction Update 10 453-467.

Manning AW, Rajkumar K, Bristol F, Flood PF \& Murphy BD 1987 Genetic and temporal variation in serum concentrations and biological activity of horse chorionic gonadotrophin. Journal of Reproduction and Fertility 35 389-397.

Mapletoft RJ, Steward KB \& Adams GP 2002 Recent advances in the superovulation in cattle. Reproduction, Nutrition, Development 42 601-611.

Matzuk MM, Hsueh AJ, Lapolt P, Tsafriri A, Keene JL \& Boime I 1990 The biological role of the carboxyl-terminal extension of human chorionic gonadotropin beta-subunit. Endocrinology 126 376-383.

McGowan MR, Braithwaite M, Jochle W \& Maplecoft RJ 1985 Superovulation of beef heifers with Pergonal (HMG): a dose-response trial. Theriogenology 24 173-184.

McNeilly AS \& Fraser HM 1987 Effect of gonadotrophin-releasing hormone agonist-induced suppression of LH and FSH on follicle growth and corpus luteum function in the ewe. Journal of Endocrinology 115 (Suppl 1) 273-282.

McNeilly AS, Jonassen JA \& Fraser HM 1986 Suppression of follicular development after chronic LHRH immunoneutralization in the ewe. Journal of Reproduction and Fertility 76 481-490.

Murphy BD, Mapletoft RJ, Manns J \& Humphrey WD 1984 Variability in gonadotrophin preparations as a factor in the superovulatory response. Theriogenology 21 117-125.

Palagiano A, Nesti E \& Pace L 2004 FSH: urinary and recombinant. European Journal of Obstetrics, Gynecology, and Reproductive Biology 115 S30-S33.

Phillips DJ, Hudson NL, Lun S, Condell LA \& McNatty KP 1993 Biopotency in vitro and metabolic clearance rates of five pituitary preparations of follicle stimulating hormone. Reproduction, Fertility, and Development 5 181-190.

Picton HM, Tsonis CG \& McNeilly AS 1990 FSH causes a time-dependent stimulation of preovulatory follicle growth in the absence of pulsatile LH secretion in ewes chronically treated with gonadotrophin-releasing hormone agonist. Journal of Endocrinology 126 297-307.

Pierce JG \& Parsons TF 1981 Glycoprotein hormones: structure and function. Annual Review of Biochemistry 50 465-495.

Richards JS 1980 Maturation of ovarian follicles: actions and interactions of pituitary and ovarian hormones on follicular cell differentiation. Physiological Reviews 60 51-89.
Ruddon RW, Sherman SA \& Bedows E 1996 Protein folding in the endoplasmic reticulum: lessons from the human chorionic gonadotropin beta subunit. Protein Science 5 1443-1452.

Sakurai H, Adams BM \& Adams TE 1992 Pattern of gonadotropin-releasing hormone $(\mathrm{GnRH})$-like stimuli sufficient to induce follicular growth and ovulation in ewes passively immunized against GnRH. Biology of Reproduction 47 177-184.

Saumande J 1980 Concentrations of luteinizing hormone, oestradiol-17beta and progesterone in the plasma of heifers treated to induce superovulation. Journal of Endocrinology 84 425-437.

Smith PL, Kaetzel D, Nilson J \& Baenziger JU 1990 The sialylated oligosaccharides of recombinant bovine lutropin modulate hormone bioactivity. Journal of Biological Chemistry 265 874-881.

Sugahara T, Pixley MR, Minami S, Perlas E, Ben-Menahem D, Hsueh AJ \& Boime I 1995 Biosynthesis of a biologically active single peptide chain containing the human common alpha and chorionic gonadotropin beta subunits in tandem. PNAS 92 2041-2045.

Sugahara T, Sato A, Kudo M, Ben-Menahem D, Pixley MR, Hsueh AJ \& Boime I 1996 Expression of biologically active fusion genes encoding the common alpha subunit and the follicle-stimulating hormone beta subunit. Role of a linker sequence. Journal of Biological Chemistry 271 10445-10448.

Thotakura NR \& Blithe DL 1995 Glycoprotein hormones: glycobiology of gonadotrophins, thyrotrophin and free alpha subunit. Glycobiology 5 3-10.

Yen SS, Llerena O, Little B \& Pearson OH 1968 Disappearance rates of endogenous luteinizing hormone and chorionic gonadotropin in man. Journal of Clinical Endocrinology and Metabolism 28 1763-1767.

Zelinski-Wooten MB, Hutchison JS, Hess DL, Wolf DP \& Stouffer RL 1995 Follicle stimulating hormone alone supports follicle growth and oocyte development in gonadotrophin-releasing hormone antagonist-treated monkeys. Human Reproduction 10 1658-1666.

Received in final form 19 November 2007

Accepted 10 December 2007

Made available online as an Accepted Preprint 10 December 2007 